\title{
Finite element analysis of the thermal behavior of a RepRap 3D printer liquefier
}

\author{
R. Jerez-Mesa*, J.A. Travieso-Rodriguez, X. Corbella, R. Busqué, G. Gomez-Gras
}

Mechanical Engineering Department, Escola Universitària d'Enginyeria Tècnica Industrial de Barcelona, Universitat Politècnica de Catalunya, C/ Comte d'Urgell, 187, Barcelona, Spain

\section{A R T I C L E I N F O}

\section{Article history:}

Received 15 October 2015

Revised 16 February 2016

Accepted 21 April 2016

Available online $\mathrm{xxx}$

\section{Keywords:}

3D printing

RepRap

Fused filament fabrication

FEM

Liquefier

Heat transfer

\begin{abstract}
A B S T R A C T
The aim of this paper is to analyze the performance of a RepRap 3D printer liquefier by studying its thermal behavior, focusing on the convective heat dissipation developed along the liquefier body during the $3 \mathrm{D}$ printing process of a workpiece. More specifically, this work tackles with the influence of the airflow generated by a fan coupled to the extruder, on the heat transfer mechanisms during the printing process. The airflow is thus taken as the variable of study. The temperature at the top of the liquefier body, where a low temperature is desirable for the correct preservation of the $3 \mathrm{D}$ printer components, is analyzed to assess the results for the different printing conditions.

For the development of this study, a finite elements model was used to determine the theoretical temperature profile of the liquefier in a steady state working regime. This mathematical model was then validated with experimental data registered with four thermocouples fixed on the tested extruder. The data was taken for different airflows, finding a relation between printing parameters and resulting temperature profile. The liquefier used for experimental data acquisition was the BCNozzle model, designed by the BCN3D Technologies of the Polytechnic University of Catalonia.

Determining the correct working parameters is necessary to optimize the fused filament fabrication process on which $3 \mathrm{D}$ printing is based, ensuring a suitable temperature distribution along the liquefier body. This would allow a correct position of the melting front along the liquefier channel, and at the same time, a non-excessive temperature at its top, next to the feeding mechanism. This is the relevance of this study, through which a model is obtained to analyze the heat transfer mechanisms, applicable for other working regimes and other extruders based on the same working principles.
\end{abstract}

(c) 2016 Elsevier Ltd. All rights reserved.

\section{Introduction}

3D printing is one of the main drivers of innovation in the manufacturing technology field worldwide. It is a generic term used to define any kind of additive or layered manufacturing process, that is, a group of techniques used to obtain final parts or prototypes in a short period of time from a CAD file by progressive addition of a raw material. Stereolitography (SLA), laminated object manufacturing (LOM) or fused filament fabrication (FFF) are some of these processes. They differ mainly in the state of the raw material and the way it is introduced into the system [1,2]. The main advantage of these systems is the possibility of manufacturing customized parts for specific applications in a relatively short period of time [3]. The potential of 3D printing systems for achieving complicated geometries, unviable through other processes, and the feasibility of processing biocompatible materials, positions it as

\footnotetext{
* Corresponding author.

E-mail address: ramon.jerez@upc.edu (R. Jerez-Mesa).
}

a reference technology for business development [4] and the promotion of strategic fields such as bioengineering [5].

Of all the different additive manufacturing technologies, fused filament fabrication has recently inspired open source initiatives to develop 3D printing devices able to satisfy the needs of users in non-industrial contexts [6]. FFF is based on extruding a heated filament of thermoplastic (usually ABS, PLA or PC) by means of a liquefier. This liquefier is mounted on a motorized gantry, driven by a numerical control code to generate a prescribed pattern (Fig. 1). Every time a layer is completed, the liquefier ascends a controlled height, and the next layer is deposited [7].

The first desktop 3D printers were developed by a team lead by Professor Adrian Bowyer at the University of Bath, giving way to the Replicating Rapid Prototyper initiative, also known as RepRap. The result of this project was an open design of a self-reproducible 3D printer, with all results available online for other users [8]. Through the years, the availability of information about open source 3D printers has risen thanks to the contribution of innovative users and spin-off projects inspired by the RepRap 


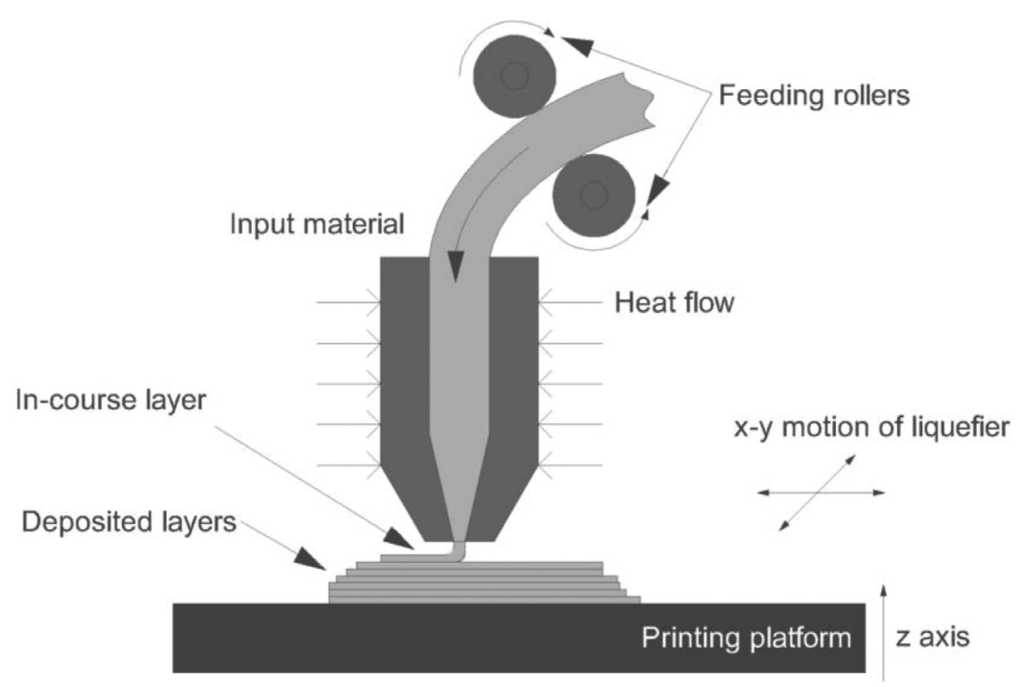

Fig. 1. Schematic representation of a Fused Filament Fabrication process.

initiative [9]. This fact has caused a rapid expansion of the technology at a domestic level, also reinforced by the low price of these open source devices. The expansion has also reached educational centers, were 3D printing is used as an innovative educative resource [10]. Along with the development of technical matters about open source 3D printing, economic aspects have also been tackled, defining methods to calculate the actual costs of desktop manufacturing, and contributing for a wider knowledge of the system $[11,12]$.

Regardless of the growth of community knowledge that has promoted the expansion of the technology, the lack of tested and scientific knowledge about the actual behavior of open source 3D printers is also noteworthy. Some of the technical solutions for critical stages of the process, such as the extruding mechanism, have been actually solved by combining commercial parts with no design background, but a remarkable empirical amateur-like approach. These aspects must be studied and enhanced so that RepRap 3D printers can become a reliable and robust desktop manufacturing system $[13,14]$.

This paper tackles with one of the sub-phases of the thermal sequence involved in a FFF manufacturing process. Thermal history and behavior of a FFF system is a critical aspect to be studied, as the final mechanical properties of the 3D printed parts have proved to be highly dependent on the bond strength between filaments, consequence of that process [15-18]. On the other hand, warp deformation is a defect often present in parts obtained by FFF. The deformation observed at FFF printed parts is caused by the thermal stresses acquired during the hot extrusion of the material, and are therefore consequence of the thermal behavior of the system [19-21]. Although the deposition strategy of the material is highly influential on the results, deepening into the thermal behavior of the liquefier regardless of its translation is an ineludible step to enhance the dimensional accuracy and mechanical strength of parts manufactured through FFF $[22,23]$.

Many authors have developed mathematical models to understand the thermal behavior of the FFF process. Bellini et al. [24] developed a mathematical model to predict the behavior of liquefiers, finding a transfer function to explain the behavior of the process [24]. Other authors have focused their efforts on defining 2-dimensional FEM to predict the position of the melt front inside a certain liquefier geometry, predicting the pressure drop of the melt flow, and confirming the results experimentally [25-29]. However, these authors do not tackle with the external evolution of the liquefier temperature and its impact on the $3 \mathrm{D}$ printer hardware, as is the objective of this paper.

The thermal process in a FFF system takes place at the liquefier, where the heating and extrusion of the semi-molten plastic is performed. The input material is fed into the heated liquefier, typically through pinch rollers activated by a motor with enough force to overcome the constriction at the tip of the nozzle. As it descends along the liquefier body, the temperature rises over the plastic glass transition point, and the material is finally extruded through the tip of a nozzle. A set of thermocouples monitors the temperature of the whole system, in order to keep it as constant as possible through a feedback loop system processed by an opensource Arduino board. The temperature specifications must comply with two conditions. First, the temperature at the nozzle must be kept constant to guarantee a continuous flow of material, and not blocking the tip of the nozzle. Secondly, the temperature must be properly decreased along the liquefier body, reaching ambient temperature at its top. This is necessary to guarantee that the $3 \mathrm{D}$ liquefier supporting elements, made of PLA or ABS, are not harmed by hot weakening. For this reason, open source 3D printer extruders have different mechanisms to prevent heat conduction towards the upper side of the liquefier.

The extruder used for this paper is a BCNozzle liquefier, designed by the RepRap Barcelona project at the BCN3D Technologies Foundation. In this kind of liquefiers, the required decrease in temperature along the liquefier body is produced by means of two mechanisms. First, a heat barrier made of low-conductive stainless steel separates the heated nozzle of the upstream part of the liquefier. Second, a fan attached to the supporting gantry executes forced convective dissipation along the liquefier body. The technological contribution of this paper consists on recommending the best working conditions of open source liquefiers refrigerated by forced convection, and study the thermal behavior of the whole system through finite elements modeling (FEM). More specifically, different airflow velocities are tested, and their influence on the extruding process of the thermal behavior is analyzed. First, the finite elements model is explained, specifying the system domains, governing equations and boundary conditions. The results are then validated through an experimental setup, where the temperature of the liquefier is measured at different point with thermocouples. The result is a recommendation about the correct functioning conditions, which is the main technological contribution of this paper. 


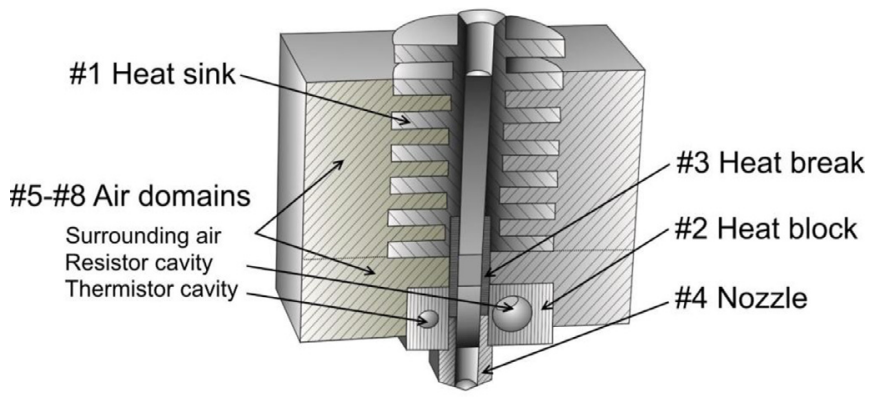

Fig. 2. Section of the geometrical domains defined in the FEM. Parts \#1, \#2, \#3 and \#4 combined compose the liquefier body.

\section{Finite elements model}

The thermal behavior of a fused filament fabrication process results from the combination of two heat transport mechanisms. First of all, the liquefier is heated up by a resistor embedded inside the heat block. Secondly, convective heat dissipation forced by an airflow caused by a fan coupled to the liquefier dissipates heat from the extruder metallic body. A FEM was developed to analyze the thermal performance of the liquefier during the extruding process, depending on the air velocity induced by the refrigeration fan. The variable of analysis is the temperature at the top of the liquefier body, $\mathrm{T}_{\mathrm{T}}$. The chosen software to perform the finite elements analysis (FEA) was COMSOL Multiphysics 4.4. The following lines describe the geometry of the model, the boundary and initial conditions and the mesh convergence study.

\subsection{Geometry and FEM domains}

The geometry of the whole system has been recreated at the FEM, and is composed of eight different domains, that is, single geometrical units with different characteristics (Fig. 2). These domains are the four parts of the liquefier, presented below, the surrounding air, the channel along which the fan air circulates, and two different air drillings corresponding to the holes inside the heating block.

The four air domains were directly defined at the COMSOL software using the available tools. The whole system boundaries of the surrounding air were modeled as a box around the extruder, so that the air domains were defined as the difference of that box and the liquefier domains skin.

The four parts of the liquefier (being one single domain each) were defined in a SolidWorks CAD model, and imported to COMSOL through the LiveLink® interface, which facilitates the redefinition of the liquefier by refreshing the FEM geometry if a change is ever performed at the SolidWorks file (Fig. 3). These four parts are described as follows:

- Heat block (\#2). A heating resistor is embedded inside, and is turned on during the printing process. It is therefore responsible for the main heat inflow into the system, directly increasing the nozzle temperature at the level set up by the user. A thermistor is embedded in the block inside a second hole, to monitor the evolution of its temperature. The regulating system is a simple feedback loop. The monitored temperature is compared with the objective temperature established by the user. When that difference is higher than a certain threshold, the resistor is turned off. On the contrary, it turns on when the temperature is too low. The temperature at the heating block is therefore never totally constant, but behaves as a typical balancing feedback loop system.

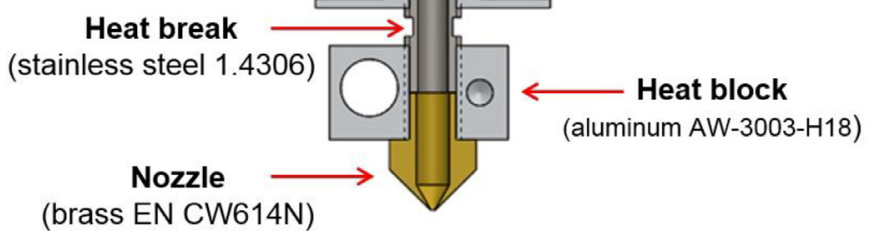

Fig. 3. Section of the analyzed BCNozzle liquefier and materials, showing the different components.

- Nozzle (\#4). This part is heated by conduction from the heat block, so that the hot extrusion is directly developed in it. The diameter of the tip (usually from 0.3 to $1 \mathrm{~mm}$ ) regulates the continuous flow of semi-melted material into the system.

- Heat break (\#3). It is the first of the protection measures composing the liquefier object of study. Constituted by a lowconductivity stainless steel, it minimizes heat conduction towards the top of the liquefier. For that purpose, it is directly attached to the heat block. Nevertheless, as this barrier is not enough, dissipation by forced convection is needed.

- Heat sink (\#1). Finned surface that favors forced convective heat dissipation. Along with the aforementioned heat break, it contributes to decrease the temperature along the liquefier body.

Once the eight different domains were defined, a material from the software library was assigned to each of them, as shown in Table 1.

\subsection{Governing equations}

The mathematical model governing the thermal behavior of the defined system was configured through the selection of the appropriate modules available in COMSOL, and explained at the following paragraph:

Module 1. 3D analysis module.

Module 2. Conjugate heat transfer \& laminar flow modules. Analysis of heat transfer in solids by conduction and convection with the surroundings, with no turbulence of the circulating fluid.

Module 3. Steady state module. The problem focuses on the 3D printer once the preparatory functions are completed and the printing process is started.

The general governing equations for the problem in the stationary state are defined at module $2[30,31]$. The air domains are governed by the continuity equation (Eq. (1)) and the Navier-Stokes equation for Newtonian fluids (Eq. (2)). For the solid domains, only the energy equation is solved (Eq. (3)).

$\nabla \cdot(\rho \mathbf{u})=0$

where $\rho$ is the fluid density and $\mathrm{u}$ is the fluid velocity.

$\rho(\mathbf{u} \cdot \nabla \mathbf{u})=-\nabla p+\nabla \cdot\left(\mu\left(\nabla \mathbf{u}+(\nabla \mathbf{u})^{\mathrm{T}}\right)-\frac{2}{3} \mu(\nabla \cdot \mathbf{u}) \mathbf{I}\right)+\mathbf{F}$ 
where $\rho$ is the fluid pressure, $\mu$ is the fluid dynamic viscosity, I is the identity matrix, $\mathrm{T}$ is the temperature and $\mathrm{F}$ are the external forces applied to the fluid.

$\rho C_{p} \mathbf{u} \cdot \nabla T=\nabla \cdot(k \nabla T)+\dot{Q}$

where, $C_{p}$ is the calorific capacity at constant pressure, $\mathrm{k}$ is the thermal conductivity, and $\dot{Q}$ is the heat flow.

\subsection{Boundary conditions and initial values}

Reaching a particular solution of the defined equations depend on the initial and boundary conditions, which have been grouped and represented as follows:

\subsubsection{Generic hypotheses}

- Planar symmetry is supposed (Fig. 4A). This first hypothesis allows to decrease computing time of the 3D model by assuming that results are to be symmetric with regards to a central plane perpendicular to the heating block cavities.

- The no-slip condition of the air on the liquefier walls was also considered, which means that the velocity of the air in contact with the liquefier walls equals zero.

- Thermal insulation of the whole system was also taken as an initial hypothesis, that is, no heat transfer of the domains with the environment. The direct consequence of this hypothesis is that that the only energy inflow at the system is the heating resistor inside the aluminum block.

\subsubsection{Circulating fluid}

The airflow is carried into the system by the fan through the inlet area shown in Fig. 4B. The fan component is therefore not physically included in the model, but represented by the normal velocity it propels into it, $u=(v, 0,0) \mathrm{m} / \mathrm{s}$. Only the longitudinal component in the direction perpendicular to the symmetry plane forms the velocity vector, being $\mathrm{v}$ the independent variable object of study. This air enters into the system at a $293.15 \mathrm{~K}$ temperature. On the other hand, the air outlet is considered thermally insulated (Fig. 4C).

\subsubsection{Conductive energy inflow}

The only heat source for the system is represented by the heat conduction originated at the resistor hole (Fig. 4D). A constant heat flow through the represented cylinder has been defined to model this inflow.

\subsubsection{Other Initial values}

A constant $1 \mathrm{~atm}$ atmospheric pressure and a $293.15 \mathrm{~K}$ temperature are set as initial values for the whole physical system. No change of pressure or temperature at the surroundings is reflected in the model.

\subsection{Mesh convergence study}

The convergence study was carried out setting a maximum relative error of $2 \%$, and using as a reference the temperature reached at the top of the liquefier channel (the opposite point with respect to the tip of the nozzle). The FEM was simulated for five different meshes that were defined in COMSOL, each one with increasing number of elements, from extremely coarse to normal (Fig. 5). The fixed airflow velocity for the convergence study was $u=(0.3$, $0,0) \mathrm{m} / \mathrm{s}$. Fig. 6 shows the relative error achieved with each mesh, with respect to the normal mesh. According to the prefixed criterion, the selected mesh for all the experiments was the "coarser" mesh. 

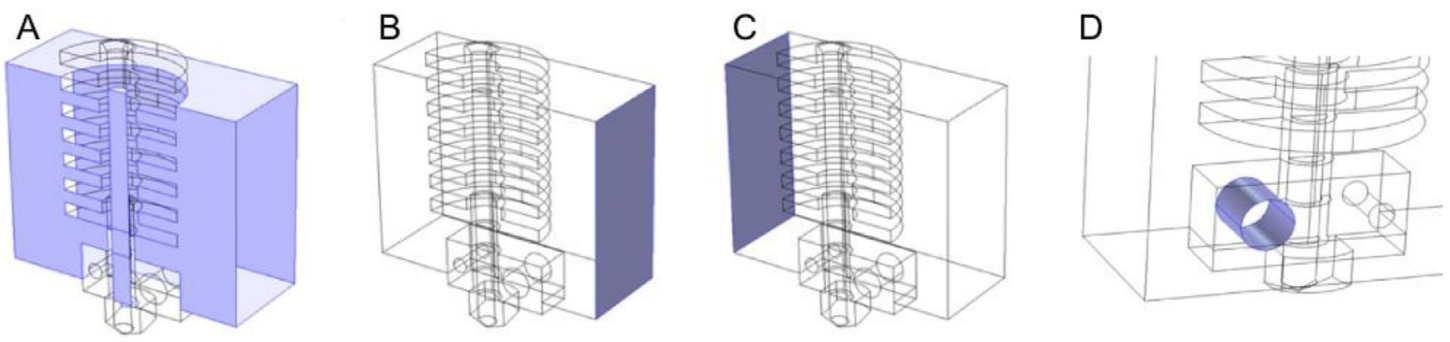

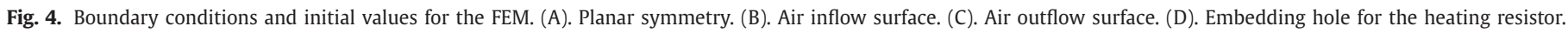
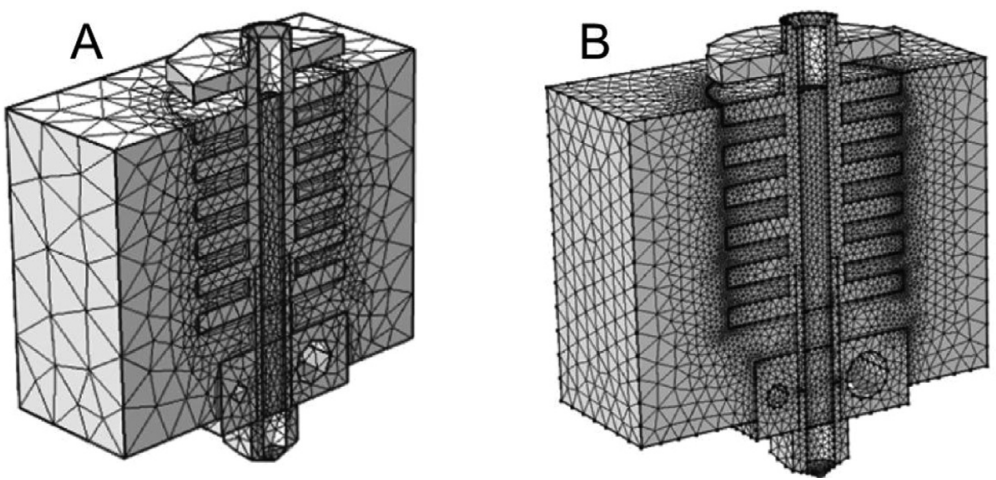

Fig. 5. (A). Extremely coarse mesh with 28,166 elements. (B). Normal mesh with 386,950 elements.

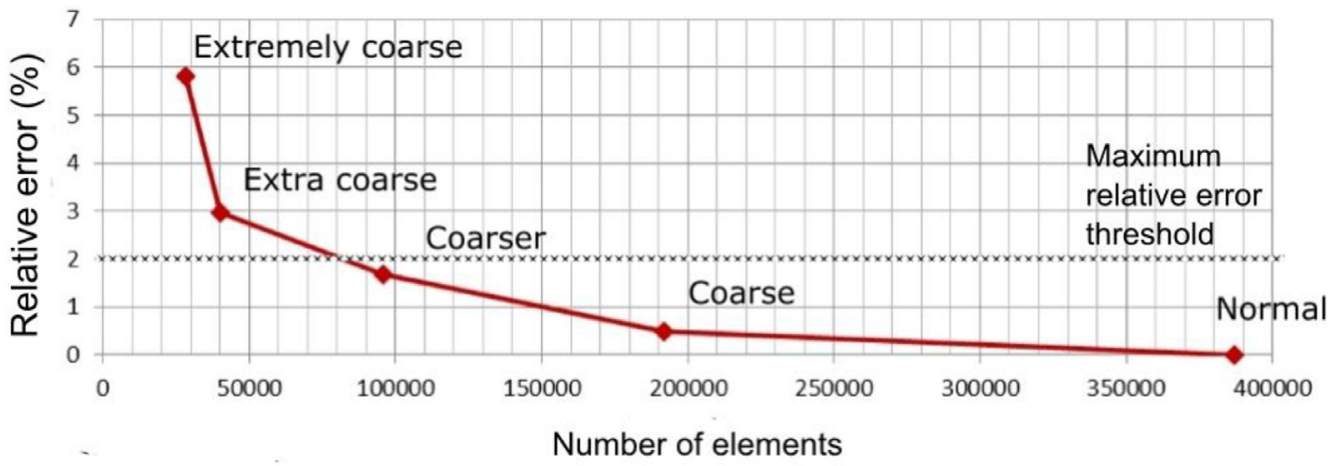

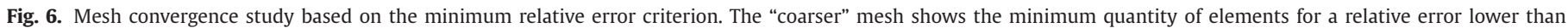
$2 \%$.

\subsection{Model simulation}

The defined FEM was executed for different cases, varying the value of the air velocity generated by the fan, from $0 \mathrm{~m} / \mathrm{s}$ to $1 \mathrm{~m} / \mathrm{s}$, and obtaining a collection of continuous graphs showing the respective temperature profiles for each of them. The simulation required a total of 8 hours of CPU processing on a four Intel(R) Core(T) i5 CPU M560@2.67 GHz with 12 GB RAM, on a Windows 7 operating system with 64 bits and 15 GB of hard disk storage.

\section{Experimental setup}

Experiments were carried out to register the temperature at equidistant points along the heat sink temperature profile in a steady state, with the objective of comparing them with the proposed computational fluid dynamics design implemented through the FEM, and calibrating the actual air flow velocity generated by the fan.

For the development of the experiments, open source equipment for RepRap 3D printers was used, and attached on a RepRap Mendel support structure. The BCNozzle liquefier was equipped as shown in Fig. 7A. A resistor and a thermistor were embedded inside their corresponding hole inside the aluminium heating block. Then, four thermocouples were attached to the external wall of the heat sink channel at four different levels, including the top of the liquefier body and the lower point coinciding with the heat barrier. Separated $25 \mathrm{~mm}$ from the liquefier, a SanAce40 Sanyo Denki fan was installed, as shown in Fig. 7B.

The last step for the experimental setup was connecting all the equipment to the ARDUINO board. The standard ARDUINO-Marlin system allowed to regulate the fan velocity, the heat generated by the resistor, and monitoring the heat block temperature through the embedded thermistor. The temperatures measured by the thermocouple were registered through a sampler device, and processed and visualized at the computer with the PLW recorder. A diagram of the whole system is represented in Fig. 8.

The software used to control the heating temperature and the fan speed was the Repetier Host freeware. Starting from a room temperature, the temperature of the heat block was set to 210 ${ }^{\circ} \mathrm{C}$, simulating the extrusion process of PLA material. The system works by a simple balancing feedback loop, that is, the thermistor records the temperature evolution, and the resistor is kept on 
A

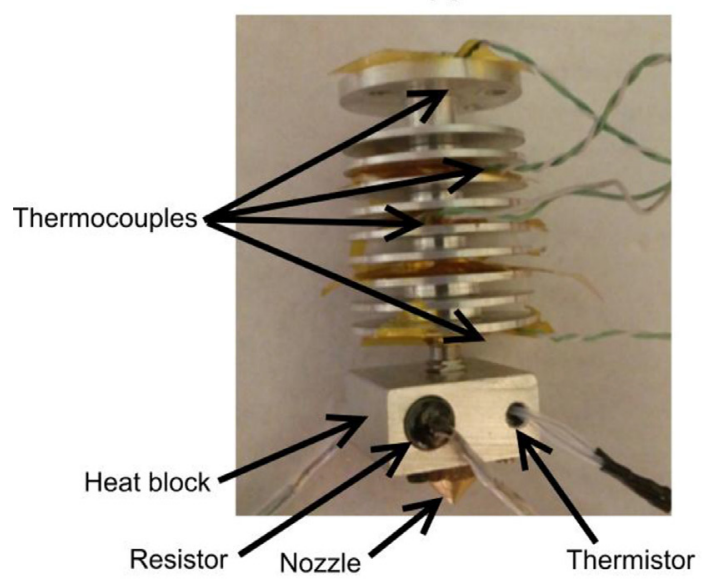

B

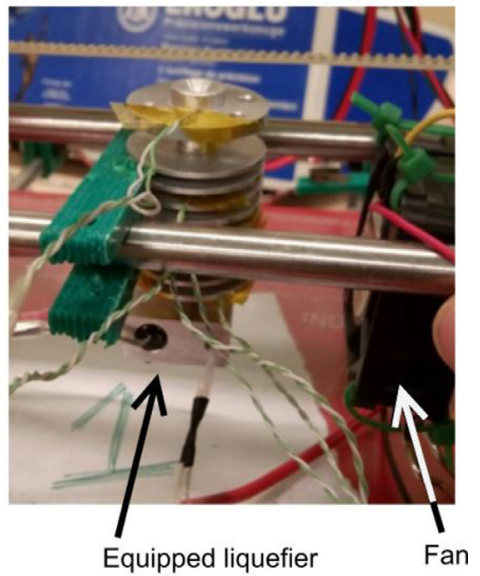

Fig. 7. (A). Overview of tested BCNozzle liquefier. (B). Fan and extruder fixed to the $\mathrm{x}$ axis 3D printer rails.

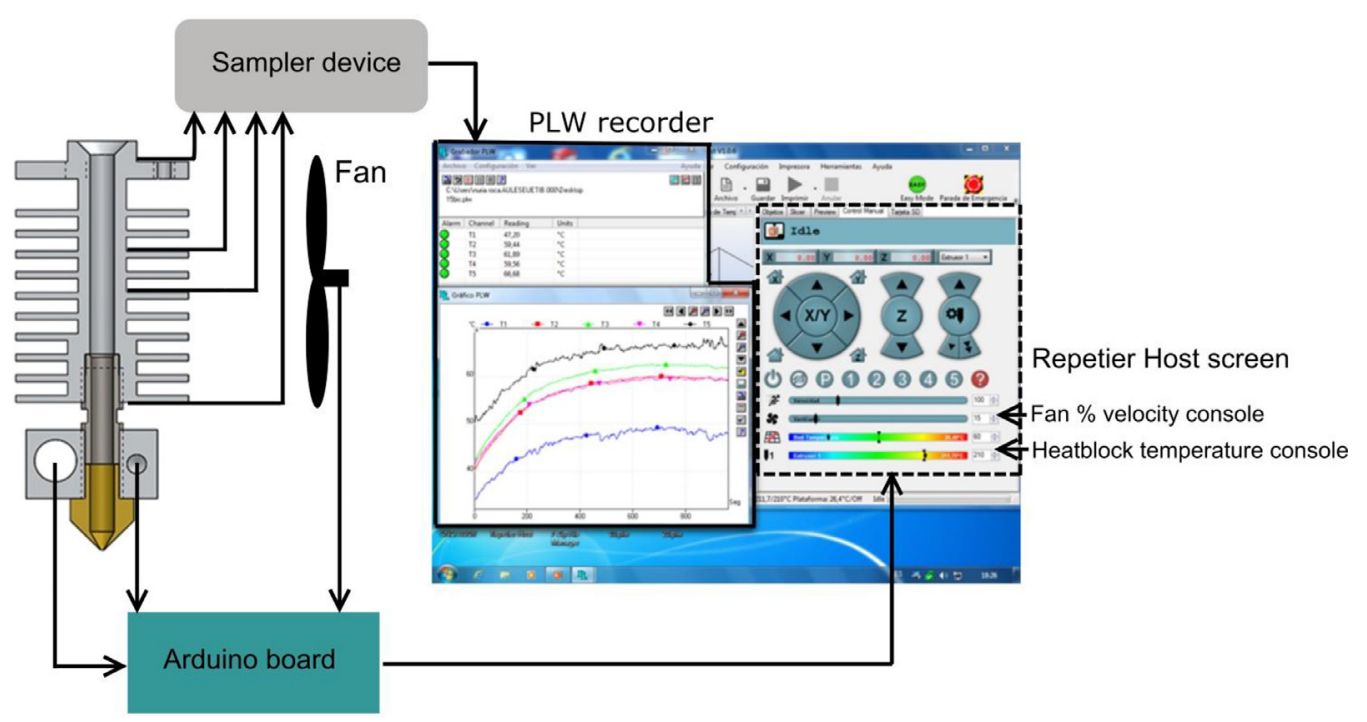

Fig. 8. Diagram of connections and software overview for the monitoring and regulation of magnitudes.

until the thermistor detects that the temperature has surpassed the objective temperature. When the temperature is higher as that threshold value, the resistor turns off until it decreases once again under $210{ }^{\circ} \mathrm{C}$, and so forth. Through this ON-OFF switching process the liquefier reaches at a steady state regime, the objective temperature of $210^{\circ} \mathrm{C}$.

During the described heating process, the fan was turned on, and the thermocouples attached to the heated liquefier registered the discrete temperatures of the device in their respective points. Repetier Host allowed to change the fan velocity, so that the monitoring of temperatures was performed for five different fan velocities that derived in the respective heat dissipation processes. Repetier Host allows to establish the fan velocity in terms of a percentage of an unknown reference value. The five considered values were $10 \%, 12 \%, 15 \%, 20 \%$ and $30 \%$. For velocities higher than $30 \%$, the effect of convection on the nozzle was so remarkable that the objective temperature would never be achieved. Each experiment was repeated five times, and the average temperature was compared with the FEA results.

\section{Results discussion}

The experimental discrete values and the continuous graphs resulting from the FEA were overlaid and compared with two ob- jectives (Fig. 9A). First of all, confirming the adequacy of the defined FEM. And, on the other hand, assigning numerical values to the airflow regulated through the Repetier Host software, which is defined as percentages of an unknown quantity. The fact that the experimental and the numerical results match shows the adequacy of the initial hypotheses, and defined boundary conditions for the FEM. Fig. 9B shows the correlation of the air velocity values, defined according to the FEM in absolute values and through the Repetier Host software as percentages. The case of zero velocity was not considered because eliminating the convective heat dissipation during a printing with a RepRap device is unadvisable.

The results show a linear correlation, and the fitting line is obtained by least squares and shown in Eq. (4), where the air velocity percentage is the independent variable, and a numerical value for the airflow velocity is the dependent variable. The regression shows a correlation factor of $\mathrm{R}^{2}=0.9826$, a high enough value so to confirm the adequacy of the FEM, as it fits with the experimental evidence.

$y=0.0391 x-0.1511$, For $10 \leq x \leq 30$.

Once accepted the FEM analysis as correct, the analysis must be focused on the $\mathrm{T}_{\mathrm{T}}$ results, which significantly varies depending on the fan velocity (Table 2). There is a negative correlation between airflow velocity and $\mathrm{T}_{\mathrm{T}}$, as the minimum temperature is achieved 


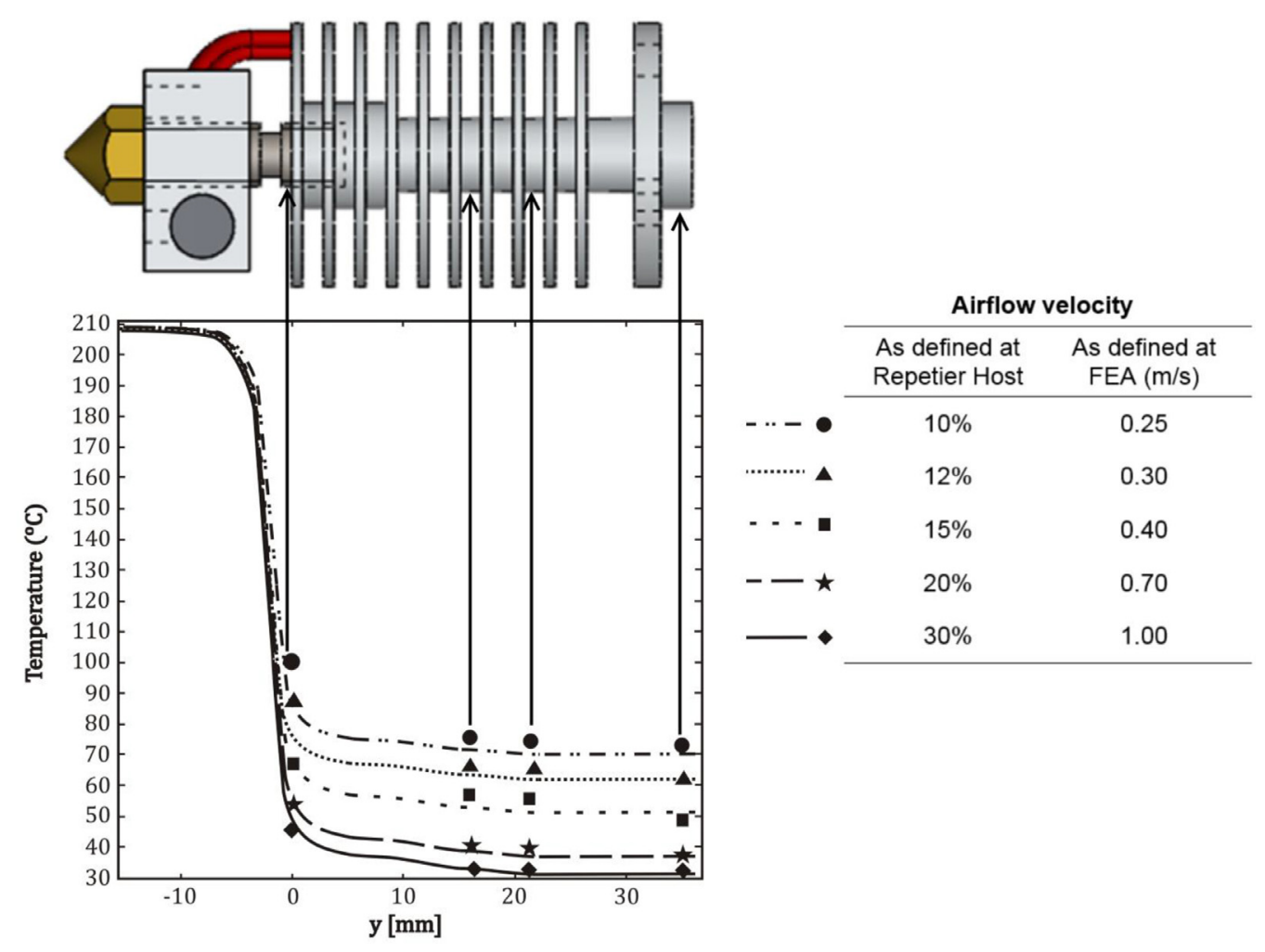

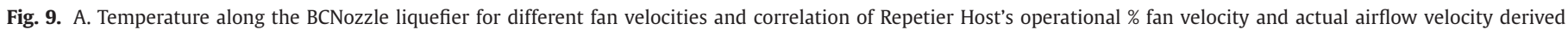
from the FEM. Dots: temperatures measured with thermocouples. Lines: results of FEM analysis.

Table 2

Temperature at the top of the liquefier, $\mathrm{T}_{\mathrm{T}}$, obtained from the FEM analysis.

\begin{tabular}{ll}
\hline Airflow velocity $(\mathrm{m} / \mathrm{s})$ & $\mathrm{T}_{\mathrm{T}}\left({ }^{\circ} \mathrm{C}\right)$ \\
\hline 0.25 & 72.2 \\
0.30 & 61.5 \\
0.40 & 50.7 \\
0.70 & 36.7 \\
1.00 & 31.1 \\
\hline
\end{tabular}

when the fan operates at the highest tested fan velocity. An exponential regression model relates both variables and approximate it to Eq. (5), with a correlation factor of $\mathrm{R}^{2}=0.992$.

$y=30.574 x^{-0.567}$, For $0.25 \leq x \leq 1.00$.

This equation relating the airflow velocity and $\mathrm{T}_{\mathrm{T}}$ can help to decide the fan velocity to use during a printing operation, depending on the desired $\mathrm{T}_{\mathrm{T}}$ for the studied interval.

\section{Conclusions}

A FEM was designed and run to study the thermal performance of a liquefier depending on the airflow velocity introduced by the refrigerating fan. Then, an experimental setup was prepared to measure discrete temperatures along the body of an open source $3 \mathrm{D}$ printer liquefier in a steady state working regime, i.e., with a preset extrusion temperature corresponding to a PLA material. During the different experiments, the velocity of the fan was changed to evaluate the influence of different airflows on the temperature of the top point of the liquefier body. The resulting temperature profiles were compared with discrete temperature values registered through an experimental setup to confirm the adequacy of the model.
The conclusions derived from the undertaken analysis are:

1. The described model defined in COMSOL Multiphysics (geometry and initial and boundary conditions) is adequate to predict the temperature profile of a $3 \mathrm{D}$ printer with the BCNozzle liquefier for different working conditions.

2. The performance of heat dissipation by convection shows a relevant influence in the final temperature achieved at the top of the liquefier, $\mathrm{T}_{\mathrm{T}}$, so the refrigerating fan must not be left out when extruding PLA with a BCNozzle extruder.

3. The airflow velocity caused by the fan can be expressed as a numerical value, and assigned to a percentage value as defined in the Repetier Host software, existing a linear relationship between both notations, for the studied values (between $10 \%$ and $30 \%)$.

4. When extruding PLA material at $210{ }^{\circ} \mathrm{C}$, the SanAce 40 Sanyo Denki fan shows a relevant influence on $\mathrm{T}_{\mathrm{T}}$, reducing it until $31.1{ }^{\circ} \mathrm{C}$, when working at a $30 \%$ of its power as defined in the Repetier Host software. An exponential relationship between airflow velocity and $\mathrm{T}_{\mathrm{T}}$ can be found for the studied interval of $0.25-1 \mathrm{~m} / \mathrm{s}$.

5. Further research evaluating the impact of overheat at the top of the liquefier, may reveal the maximum acceptable temperature at the top of the liquefier, to reduce the fan working regime with the consequent energy saving.

\section{References}

[1] Bikas H, Stavropoulos P, Chryssolouris G. Additive manufacturing methods and modelling approaches: a critical review. Int J Adv Manuf Tech 2015:1-17. doi:10.1007/s00170-015-7576-2.

[2] Kulkarni P, Marsan A, Dutta D. A review of process planning techniques in layered manufacturing. Rapid Prototyp J 2000;6(1):18-35.

[3] Berman B. 3-D printing: the new industrial revolution. Bus Horizons 2012;55(2):155-62. 
ARTICLE IN PRESS

ID: $\mathrm{MECH}$

[m5G;April 28, 2016;20:12]

8

R. Jerez-Mesa et al./Mechatronics 000 (2016) 1-8

[4] Reyna T, Striukova L. From rapid prototyping to home fabrication: how 3D printing is changing business model innovation. Technol Forecast Soc 2016;102:214-24

[5] Huang SH, tiu P, Mokasdar A, How L. Additive manufacturing and its societal impact: a literature review. Int J Adv Manuf Tech 2013;67(5-8):1191-203.

[6] Günther D, Heymel B, Günther JF, Ederer I. Continuous 3D-printing for additive manufacturing. Rapid Prototyping J 2014;20(4):320-7.

[7] Turner N, Strong B, Gold SA. A review of melt extrusion additive manufacturing processes: I. Process design and modeling. Rapid Prototyping J 2014;20(3):192-204.

[8] RepRap Project Wiki. www.reprap.org. Last retrieved on 08/10/2015

[9] Kentzer J, Koch B, Whim M, Jones RW, Villumsen E. An open source hardware-based mechatronics project: The replicating rapid 3-D printer. In: Proceedings of the th international conference on mechatronics; 2011. p. 18.

[10] Kostakis V, Niaros V, Giotitsas C. Open source 3D printing as a means of learning: an educational experiment in two high schools in Greece. Telemat Infermat 2015;32(1):118-28.

[11] Pereira Milo CH, Calandrin Martins R, Rosa Parma B, de Oliveira Pamplona E, Comes Salgado E, Tavares Seguso R. Systematic proposal to calculate price of prototypes manufactured through rapid prototyping an FDM 3D printer in a university lab. Rapid Prototyp J 2010;16(6):411-16.

[12] Wittbrodt BT, Glover AG, Laureto J, Anzalone GC, Oppliger D, Irwin JL, et al. Life-cycle economic analysis of distributed manufacturing with opensource 3-D printers. Mechatronics 2013;23(6):713-26.

[13] Ciurana J, Serenoa L, Wales E. Selecting process parameters in RepRap additine manufacturing system for PLA scaffolds manufacture. In: Procedia CIRP, 5; 2013. p. $152-7$.

[14] Lanzotti A, Del Giudice DM, Lepore A, Staiano G, Martorelli M. On the geometic accuracy of reprap open-source three-dimensional printer. J Mech Design 2015;137(10):101703.

[15] Sun Q, Rizvi GM, Bellehumeur CT, Gu P. Effect of processing conditions on the bonding quality of FDM polymer filaments. Rapid Prototyp J 2008;14(2):7280.

[16] Thomas JP, Rodriguez JF. Modeling the fracture strength between fused deposition extruded roads. In: Proceedings of the 11 th solid freeform fabrication symposium, Texas, USA; 2000.
[17] Bellini A, Güçeri S. Mechanical characterization of parts fabricated using fused deposition modeling. Rapid Prototyp J 2003;9(4):252-64.

[18] Bellehumeur C, Li L, Sun Q Gu P. Modeling of bond formation between polymen filaments in the fused deposition modeling process. J Manuf Processes 2004;6(2):170-8.

[19] Chang Y, Chou K. A parametric study of part distortions in fused deposition modelling using three-dimensional finite element analysis. P I Mech Eng B-J Eng 2008;222(8):959-68.

[20] Wang TM, Xi JT, Jun Y. A model research for prototype warp deformation in the FDM process. Int J Adv Manuf Tech 2007;33(11-12):1087-96.

[21] Nickel AH, Barnett DM, Prinz FB. Thermal stresses and deposition patterns in layered manufacturing. Mater Sci Eng A Struct 2001;317(1):59-64.

[22] Yardimci MA, Güçeri S. Conceptual framework for the thermal process modfling of fused deposition. Rapid Prototyp J 1996;2(2):26-31.

[23] Domingo-Espin M, Puigoriol-Forcada JM, Garcia-Granada AA, Lluma J, Borros S, Reyes G. Mechanical property characterization and simulation of fused depositon modeling Polycarbonate parts. Mater Design 2015;83:670-7.

[24] Bellini A, Guçeri S, Bertoldi M. Liquefier dynamics in fused deposition. J Manuf Sci E-T ASME 2004;126(2):237-46.

[25] Yarimci MA, Hattori T, Guceri I, Danforth SC. Thermal analysis of fused deposition. In: Proceedings of solid freeform fabrication conference; 1997. p. 689698.

[26] Ramanath HS, Chur CK, Leon KF, Shah KD. Melt flow behaviour of poly- $\varepsilon$-caprolactone in fused deposition modelling. J Mater Sci-Mater M $2008 ; 19(7): 2541-50$.

[27] Zhang Y, Chou YK. Three-dimensional finite element analysis simulatrons of the fused deposition modelling process. P I Mech Eng B-J Eng 2006;220(10):1663-71.

[28] Nikzad M, Syed HM, Igor S, Andrew G. A study of melt flow analysis of an ABS-Iron composite in fused deposition modelling process. Tsinghua Sci Tech 2009;14:29-37.

[29] Nikzad M, Masood SH, Sbarski I. Thermo-mechanical properties of a highly filled polymeric composites for fused deposition modeling. Mater Design 2011;32(6):3448-56.

[30] Barbu V. Stabilization of Navier-Stokes Flows. 1st ed. London: Springer; 2011.

[31] Ready JN, Gatling DK. The finite element method in heat transfer and fluid dynamics. 3rd ed. New York: CRC Press, Taylor \& Francis Group; 2010.

Please cite this article as: R. Jerez-Mesa et al., Finite element analysis of the thermal behavior of a RepRap 3D printer liquefier, Mecha-

tronics (2016), http://dx.doi.org/10.1016/j.mechatronics.2016.04.007 